\title{
Endoscopic submucosal dissection with a ligation device for the treatment of rectal carcinoid tumor
}

Rectal carcinoid tumor is a relatively rare tumor, which is occasionally found during screening colonoscopy. Tumors less than $1 \mathrm{~cm}$ in diameter and limited in depth to the submucosal layer can be managed by endoscopic treatment, several types of which have been reported for rectal carcinoid tumor $[1,2]$. Because carcinoid tumor extends to the submucosal layer, simple endoscopic mucosal resection (EMR) will often leave tumor involvement in the deeper tissue levels [3]. Recently the technique of endoscopic submucosal dissection (ESD) has been shown to be useful in the treatment of rectal carcinoid tumor $[3,4]$. However, ESD requires high levels of technical skill and procedure times are long. In addition, the rate of complications, such as perforation, is higher with ESD than with EMR. To overcome this situation, we developed a new technique, known as endoscopic submucosal dissection with band ligation (ESD-L), for the treatment of rectal carcinoid tumor. This new technique is a combination of circumferential mucosal cutting and rubber band ligation ( $\bullet$ Fig. 1).

Previously, endoscopic submucosal resection with band ligation (ESMR-L) has proved to be useful for the treatment of rectal carcinoid tumor [5]. ESMR-L is a relatively simple technique; however, it is sometimes difficult to ensure that suction is being applied right at the center of the tumor, which is the most crucial part in this technique, or at least there may be uncertainty about this.

ESD-L has the accuracy of ESD and the simplicity of ESMR-L. The circumferential mucosal cutting makes it much easier to aim and suck the tumor with the ligation device. This technique is useful because there is no need to complete the submucosal dissection, which is the most difficult part in colorectal ESD. Furthermore, the band ligation will facilitate clearance of tumor from the deeper tissue levels (๑ Fig. 2).

We have performed ESD-L on three patients in our institution and no complications, such as perforation or bleeding, have been seen. In conclusion, ESD-L may be a simple and reliable technique for the treatment of rectal carcinoid tumor.
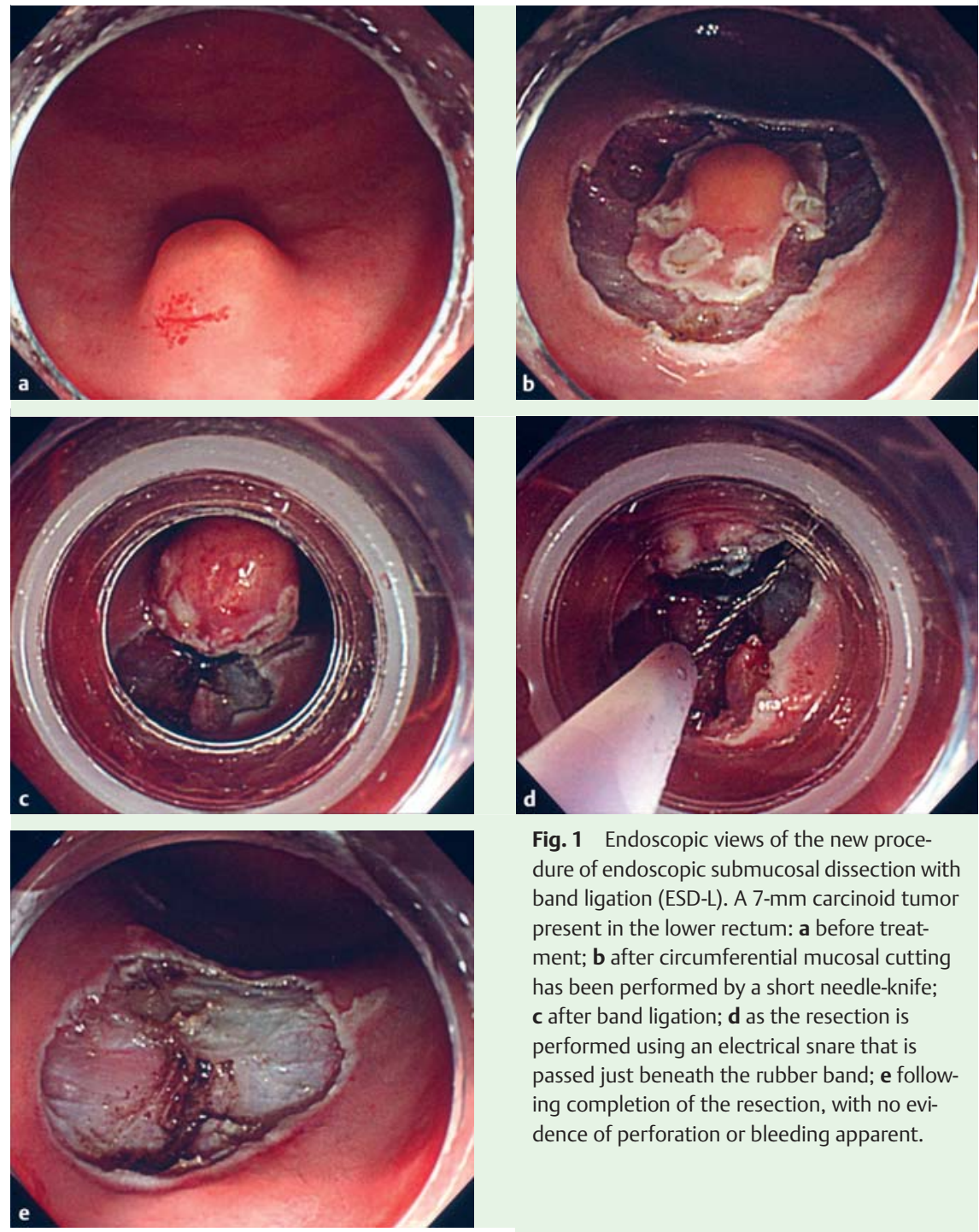

Fig. 1 Endoscopic views of the new procedure of endoscopic submucosal dissection with band ligation (ESD-L). A 7-mm carcinoid tumor present in the lower rectum: $\mathbf{a}$ before treatment; $\mathbf{b}$ after circumferential mucosal cutting has been performed by a short needle-knife; $\mathbf{c}$ after band ligation; $\mathbf{d}$ as the resection is performed using an electrical snare that is passed just beneath the rubber band; e following completion of the resection, with no evidence of perforation or bleeding apparent.

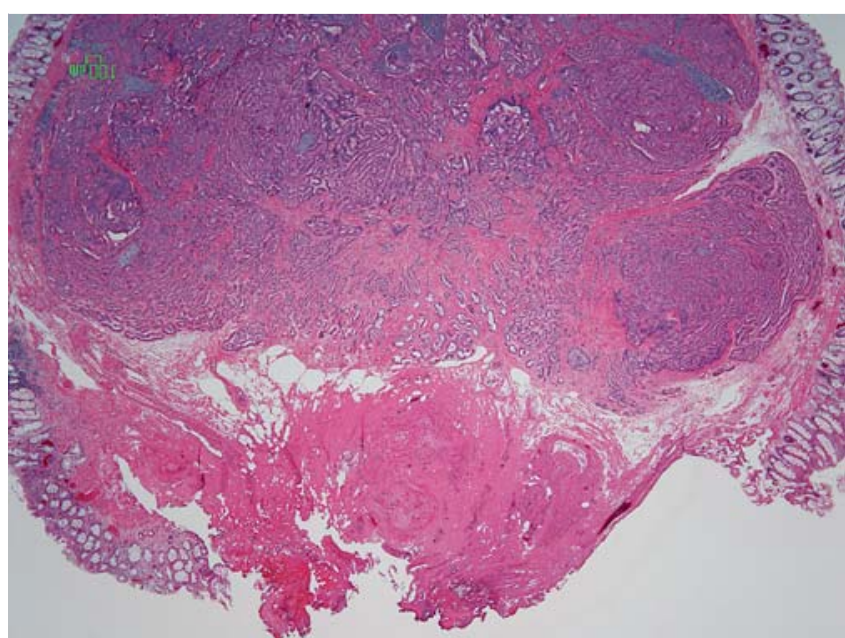

Fig. 2 Histological appearance following curative en bloc resection of a carcinoid tumor, showing that a sufficient depth of tissue to ensure clear margins can be obtained by this technique. 
Endoscopy_UCTN_Code_TTT_1AQ_2AD

Competing interests: None

T. Shida, M. Aminaka, Y. Shirai, K. Okimoto, S. Tsuruta, E. Kita, S. Tsuchiya, K. Kato, M. Takahashi Department of Endoscopy, Funabashi Central Social Insurance Hospital, Funabashi, Japan

\section{References}

1 Fujimura $Y$, Mizuno M, Takeda $M$ et al. A carcinoid tumor of the rectum removed by strip biopsy. Endoscopy 1993; 25: 428-430

2 Imada-Shirakata Y, Sakai M, Kajiyama Tet al. Endoscopic resection of rectal carcinoid tumors using aspiration lumpectomy. Endoscopy 1997; 29: $34-38$

3 Lee DS, Jeon SW, Park SY et al. The feasibility of endoscopic submucosal dissection for rectal carcinoid tumors: comparison with endoscopic mucosal resection. Endoscopy 2010; 42: 647-651

4 Yamaguchi $N$, Isomoto $H$, Nishiyama $H$ et al. Endoscopic submucosal dissection for rectal carcinoid tumors. Surg Endosc 2010; 24: 504-508

5 Ono A, Saito Y, Matsuda T et al. Endoscopic submucosal resection of rectal carcinoid tumors with a ligation device. Gastrointest Endosc 2003; 57: $583-587$
Bibliography

DOI $10.1055 / \mathrm{s}-0030-1256960$

Endoscopy 2012; 44: E4-E5

(c) Georg Thieme Verlag KG Stuttgart · New York . ISSN 0013-726X

\section{Corresponding author}

T. Shida, MD, PhD

Department of Endoscopy

Funabashi Central Social Insurance Hospital 6-13-10 Kaijin

Funabashi 273-8556

Japan

Fax: +81-47-4352655

shidax812@yahoo.co.jp 